\title{
RESÍDUOS SÓLIDOS DOMICILIARES: UM ESTUDO DE CASO EM UM MUNICÍPIO PARANAENSE
}

\author{
MONTANARI, Robson Luiz ${ }^{1}$ \\ OLIVEIRA, Ivanir Luiz de ${ }^{2}$ \\ PILATTI, Luiz Alberto ${ }^{3}$ \\ STADLER, Carlos Cezar ${ }^{4}$
}

\begin{abstract}
RESUMO: O presente estudo de caso, inicialmente, fez uma revisão bibliográfica, contemplando as bibliografias pertinentes bem como Leis e Normas sobre os resíduos sólidos domiciliares do município em estudo. Em seguida, foi feita uma entrevista com o encarregado do departamento de meio ambiente do município em estudo, a fim de se conhecer a realidade em relação à coleta dos resíduos sólidos domiciliares. Na seqüência um questionário foi aplicado a 580 moradores do município em estudo que procurou verificar a eficiência da campanha feita pelo município. Por fim, foi feita a análise dos dados, fazendo a triangulação desses com as Leis e Normas disponíveis, entrevista e questionário. Os resultados mostraram o conhecimento do município para com a legislação vigente, o serviço de coleta seletiva que atende cerca de metade dos moradores e a campanha educacional que o município está fazendo para orientar os moradores. Os resultados indicaram a necessidade de ampliar o serviço de coleta seletiva e estender o programa educacional para que este possa realmente alcançar todo o município.
\end{abstract}

Palavras-chave: Resíduos sólidos domiciliares. Coleta seletiva. Educação ambiental.

SUMMARY: Initially, a bibliographical revision was done by this present case study contemplating the pertinent bibliographies as Laws and Norms about the home solid residues of the town in study. Next, an interview was done with the foreman of the environment department of the town in study in order to find out the reality regarding the collection of the home solid residues. In the sequence a questionnaire was applied to 580 inhabitants of the town in study trying to verify the efficiency of the campaign made by the town. Finally, the analysis of the facts was done using the triangulation with the available Laws and Norms, interview and questionnaire. The results showed the knowledge of the town towards the valid legislation, the service of selective collection that attends about half of the inhabitants and the educational campaign that the town is performing to orient the inhabitants. The results also indicated the need of extending the service of selective collection and extend the educational program so that it will be able to achieve the whole town.

Keywords: Home Solid Residues; Selective Collection; Environmental Education.

\section{INTRODUÇÃO}

O processo acelerado de urbanização nas cidades brasileiras trouxe novos desafios aos municípios. Um deles é a questão dos resíduos sólidos domiciliares ou, ainda, simplesmente, o "lixo" residencial.

Os resíduos sólidos domiciliares são compostos de todo material sólido ou semi-sólido indesejável e que necessita de ser removido por ter sido considerado inútil por quem o descarta

1 UTFPR-PG - Universidade Tecnológica Federal do Paraná (Ponta Grossa) - prof_robson@terra.com.br ;

2 UTFPR-PG - lapilatti@utfpr@utfpr.edu.br

$3 \quad U T F P R-P G-c s t a d l e r @ p g . c e f e t p r . b r$

$4 \quad$ UTFPR-PG- ivanir@pg.cefetpr.br

Nucleus, v. 5. n. 1, abr. 2008 
(MONTEIRO; ZVEIBIL, 2001).

A retirada desses "lixos" descartados torna-se fundamental, pois um fator a considerar é a quantidade de "lixo" gerado diariamente. Segundo dados do Instituto Brasileiro de Geografia e Estatística (IBGE), nas cidades com até 200.000 habitantes, são recolhidos de 450 a 700 gramas de "lixo" por habitante; nas cidades com mais de 200 mil habitantes, essa quantidade aumenta para a faixa entre 800 e 1.200 gramas por habitante.

Em 2000, através de uma pesquisa nacional de saneamento básico, o IBGE constatou que eram coletadas 125.281 toneladas de "lixo" domiciliar diariamente, em todos os municípios brasileiros.

Apesar desse cenário e do crescimento desordenado de alguns municípios, segundo o IBGE, em 2002, os serviços de coleta direta ou indireta de "lixo" atingiram 95\% dos domicílios nas zonas urbanas.

O que precisa ser considerado é que, embora existindo a coleta do "lixo", os resíduos sólidos domiciliares podem oferecer riscos ao homem e ao meio ambiente. O contato dos mesmos com o meio ambiente pode, por exemplo, interagir na cadeia alimentar do homem. $\mathrm{O}$ desafio dos municípios está justamente em coletar e dar um destino correto ao "lixo".

Assim, o artigo procura, inicialmente, saber sobre coletas e o destino do "lixo" em um município paranaense. Em seguida, busca-se conhecer a existência de legislações e campanhas de orientação sobre os resíduos sólidos domiciliares no município em estudo. E, por fim, a pesquisa faz uma analise da legislação vigente e bibliografias, e das atuais atitudes da prefeitura municipal em relação à coleta e o destino do "lixo" e dos moradores do município em relação aos resíduos sólidos domiciliares.

\section{RESÍDUOS SÓLIDOS DOMICILIARES}

O aumento da população, a industrialização e o crescimento das cidades trouxeram não apenas aumento na quantidade de "lixo", mas também mudanças importantes no "lixo". Muitas embalagens ou recipientes que, até então, eram confeccionados de materiais tradicionais como, por exemplo, as garrafas de vidro dos refrigerantes, estão sendo substituídos, por outros materiais, tais como embalagens de plástico ou alumínio.

A substituição dos materiais por substâncias relativamente novas, como tentativa de diminuir a quantidade de lixo e a poluição do meio ambiente, pode representar um importante passo, pois além da alta quantidade de material coletada diariamente, alguns resíduos sólidos domiciliares podem oferecer muitos riscos.

Com objetivo de estabelecer princípios, procedimentos e critérios algumas Leis estaduais e federais buscaram regulamentar a situação. No estado do Paraná, estado do município em estudo, a Lei 12493/99 estabelece critérios referentes à geração, acondicionamento, coleta, transporte, tratamento e destinação final dos resíduos sólidos.

De acordo esta Lei, os resíduos sólidos urbanos, provenientes de residências, 
estabelecimentos comerciais e prestadores de serviços, bem como a limpeza pública urbana, deverão ter acondicionamento, coleta, transporte, armazenamento, tratamento e destinação final atendendo às normas aplicáveis da Associação Brasileira de Normas Técnicas (ABNT) e as condições estabelecidas pelo Instituto Ambiental do Paraná (IAP).

A ABNT, através da NBR 10004, faz a divisão, classificando o "lixo" por classes e de acordo com sua origem; no entanto não estabelece critérios para reutilização ou destino dos resíduos sólidos domiciliares, como mostra a Nota Técnica da ABNT sobre a utilização dos resíduos sólidos.

A NBR 10004, inicialmente, define "lixo" ou resíduo como: "restos das atividades humanas, considerados pelos geradores como inúteis, indesejáveis ou descartáveis. Normalmente, apresentam-se sob estado sólido, semi-sólido ou semilíquido".

Em seguida, faz a divisão dos resíduos de riscos potenciais ao meio ambiente, (resíduo perigoso, não inerte e inerte) nas seguintes classes:

a) Resíduo perigoso ou classe I: é aquele que pode apresentar risco à saúde pública, provocando ou contribuindo para um aumento de mortalidade ou incidência de doenças;

b) Resíduo não inerte ou classe II: é aquele que tem propriedades tais como combustibilidade, biodegradabilidade ou solubilidade em água;

c) Resíduo inerte ou classe III: é aquele cujos constituintes dissolvidos ficam em concentrações abaixo dos padrões de potabilidade.

Em relação à classificação dos resíduos, a NBR 10004 classifica-os de acordo com a sua origem sendo: lixo comercial, de varrição e de feiras livres; de serviços de saúde e hospitalar, de portos, aeroportos e terminais ferro e rodoviários, industrial, agrícola, entulhos e os resíduos sólidos domiciliares urbanos.

As classificações da ABNT, bem como as Leis e as condições estabelecidas pelo IAP devem ser levadas em consideração não só pelos municípios, mas também pelos seus habitantes. Quaisquer materiais descartados que possam pôr em risco a saúde do homem ou o meio ambiente é considerado perigoso.

Em se tratando de resíduos sólidos domiciliares, os moradores do município precisam auxiliar o município, pois, segundo a NBR 10004 da ABNT, os resíduos sólidos domiciliares são aqueles originados da vida diária das residências, constituído por restos de alimentos (tais como, cascas de frutas, verduras etc.), produtos deteriorados, jornais e revistas, garrafas, embalagens em geral, papel higiênico, fraldas descartáveis e uma grande diversidade de outros itens.

Assim, objetos como pilhas, lâmpadas fluorescentes e frascos de aerossóis estão, diariamente, presentes no "lixo" residencial. O que ocorre é o desconhecimento do perigo que esses objetos podem representar.

Para Silva (2000), as pilhas e as lâmpadas fluorescentes são classificadas como resíduos perigosos por terem metais pesados que possam migrar e vir a integrar a cadeia alimentar do homem.

Os frascos de aerossóis também são classificados como resíduos perigosos pelos restos 
de substâncias químicas que essas contêm quando descartadas. Com o rompimento do frasco, essas substâncias podem contaminar o meio ambiente, migrando para as águas superficiais ou subterrâneas (SILVA, 2000).

Nesse contexto, a participação do município com campanhas educativas e orientadoras aos moradores para separação dos resíduos sólidos domiciliares ou a implantação de coletas seletivas pode representar uma importante ferramenta para que o município possa dar um destino adequado a esses resíduos.

A coleta seletiva de "lixo" é um serviço que poderá coletar os resíduos sólidos de forma que o material possa ser reaproveitado, facilitando o processo de reciclagem e evitando o contato com o meio ambiente e o homem. O sistema pode ser implantado em bairros residenciais, escolas, escritórios, centros comerciais ou outros locais que facilitem a coleta de materiais recicláveis. Contudo, é importante que o serviço de limpeza pública do município esteja integrado com o projeto, pois, dessa forma, os resultados serão mais expressivos (CRUZ, 2002).

A participação dos moradores na coleta seletiva é fundamental, pois, na hora de descartar o "lixo" domiciliar, pode-se separar de forma a organizar os resíduos para facilitar a coleta de materiais recicláveis.

A participação do município tem continuidade importante depois da coleta, pois segundo Cruz (2002), quando o "lixo" não é tratado adequadamente, ele pode ser altamente poluente e afetar, diretamente, a saúde pública.

Depois do "lixo" coletado, segundo dados do Instituto Brasileiro de Geografia e Estatística (IBGE), o mesmo, na grande maioria dos municípios brasileiros, é depositado em lixões (depósitos a céu aberto), em aterros controlados (disposição de resíduos sólidos sem causar danos ou riscos à saúde pública) e em aterros sanitários (terreno apropriado e que obedece a normas especificas para disposição dos resíduos sólidos) como mostra a figura abaixo:

\begin{tabular}{|c|c|c|c|c|c|c|c|c|c|}
\hline \multirow{3}{*}{$\begin{array}{c}\text { Regiões, } \\
\text { Unidades da }\end{array}$} & \multicolumn{9}{|c|}{ Distritos com serviços de limpeza urbana e/ou coleta de lixo } \\
\hline & \multicolumn{9}{|c|}{ Unidades de destinação final do lixo coletado } \\
\hline & & & & & & & & & \\
\hline Federação, & & Vaza & Vaza & & & & & & \\
\hline Regiões & & douro & douro & & & & & & \\
\hline Metropolitanas & & a céu & em áreas & & & Aterro de & Usina de & & \\
\hline e Municípios & & aberto & alaga & Aterro & Aterro & resíduos & compôs & Usina de & Incine \\
\hline das Capitais & Total & (lixão) & das & controlado & sanitário & especiais & tagem & reciclagem & ração \\
\hline Brasil & 8381 & 5993 & 63 & 1868 & 1452 & 810 & 260 & 596 & 325 \\
\hline Norte & 512 & 488 & 8 & 44 & 32 & 10 & 1 & - & 4 \\
\hline Nordeste & 2714 & 2538 & 7 & 169 & 134 & 69 & 19 & 28 & 7 \\
\hline Sudeste & 2846 & 1713 & 36 & 785 & 683 & 483 & 117 & 198 & 210 \\
\hline Sul & 1746 & 848 & 11 & 738 & 478 & 219 & 117 & 351 & 101 \\
\hline Centro-Oeste & 563 & 406 & 1 & 132 & 125 & 29 & 6 & 19 & 3 \\
\hline
\end{tabular}

Figura 1: Destinação final do lixo coletado.

Fonte: IBGE, (2000).

Nota: Um mesmo município pode apresentar mais de uma unidade de destinação final do lixo coletado. 
Para Cruz (2002), os lixões são uma forma inadequada de disposição final dos resíduos sólidos municipais, e uma solução precária, também, é usada nos aterros sanitários, pois, além de não se aproveitar nada do lixo, ocupa grandes áreas, que só poderão ser usadas para ajardinamentos, dado o risco de explosão.

$\mathrm{O}$ aterro controlado é o mais adequado e caracteriza-se, segundo Monteiro; Zveibil (2001), pela coleta e tratamento do chorume (líquido poluente), assim como da drenagem e queima do biogás. O que o diferencia o lixão do aterro sanitário é exatamente o sistema de coleta de chorume.

\section{ESPECIFICAÇÕES DO CASO}

Em entrevista com o encarregado do departamento do meio ambiente da prefeitura do município em estudo, foi apurada a atual situação do município em relação aos resíduos sólidos domiciliares.

Inicialmente, constatou-se que os resíduos coletados são depositados em um aterro controlado, segundo a Lei estadual 12493/99. De acordo com o entrevistado, o aterro controlado “[...] possui alguma infra-estrutura como aterro sanitário [...]”, tendo “[...] dreno de gás, dreno de chorume" (líquido poluente) e é feito o aterramento do material semanalmente, 'às vezes' até duas vezes por semana [...]”.

Segundo o entrevistado, "a coleta regular é feita em cem por cento dos domicílios", assim "toda a população é atendida com a coleta regular do lixo"; no entanto, a coleta seletiva acontece "em torno de metade da população do município". Ou seja, cerca de cinqüenta por cento do "lixo" coletado está indo para o aterro controlado sem a devida separação.

A coleta seletiva do "lixo" domiciliar, segundo entrevistado, é feita por "[...] uma associação criada e que recebe apoio da prefeitura [...]". Ainda segundo o entrevistado, depois de “[...] feita essa coleta com o caminhão, que é da prefeitura [...]”, os resíduos sólidos domiciliares são levados para "[...] uma central de triagem, num barracão onde eles separam o plástico, o papel, o metal, o vidro; prensam este material, acondicionam a 'pra' poder ser vendido [...]'.

O município em estudo está também realizando uma campanha de orientação aos moradores do município. Segundo o entrevistado, atualmente o município tem "[...] diversos materiais, panfletos, materiais impressos, para trabalhar essa questão da educação [...]”. São feitas "[...] palestras nas escolas, nos bairros [...]" e "na semana do meio ambiente" a prefeitura "trabalhou com quatro mil crianças [...]" em escolas publicas.

O trabalho de educação nas escolas procurou, segundo o entrevistado, orientar o modo de "[...] separar, de como acondicionar; a necessidade de separar, dados sócio econômicos e ambientais $[. .$.$] ". Para o entrevistado, o trabalho deve ter continuidade para que ocorra uma$ mudança educacional, para isso, a equipe do serviço de coleta tem continuado a campanha "[...] orientando e entregando $[\ldots]$ panfletos $[\ldots]$ ao fazer a coleta $[\ldots]$ ”.

Nucleus, v. 5. n. 1 , abr. 2008 


\section{METODOLOGIA DA PESQUISA}

A metodologia voltou-se à obtenção de conhecimento científico, o que faz necessário conhecer as construções mentais que possibilitem alcançar os objetivos almejados. Para Gil (1999, p.27), isso significa a determinação do método que, segundo o autor, "é o caminho para se chegar a determinado fim".

O objeto de pesquisa deste artigo foi investigar a coleta e o destino dos resíduos sólidos domiciliares em um município paranaense. Isto representa a problemática deste artigo, pois segundo Lakatos; Marconi (2001), “o problema é uma dificuldade, teórica ou prática, no conhecimento de alguma coisa de real importância, para a qual se deve encontrar uma solução".

A pesquisa caracteriza-se como aplicada quanto a sua natureza qualitativa, quanto a sua forma e exploratória e descritiva, quanto aos seus objetivos. O método de pesquisa utilizado é o estudo de caso. Para Yin (2001), o estudo de caso é um método a ser utilizado, quando ocorre uma investigação empírica de um fenômeno dentro de seu contexto da vida real, explorando as condições entre o fenômeno e o contexto em que este está inserido.

Tendo como base o método de estudo de caso, foram adotados os seguintes procedimentos para o desenvolvimento deste artigo: a) revisão bibliográfica; b) elaboração de entrevista semiestruturada composta de questões abertas e com roteiro para condução da mesma; c) entrevista no departamento de meio ambiente do município em estudo, a fim de conhecer melhor a atual situação do município em relação à coleta dos resíduos sólidos domiciliares; d) elaboração de questionário com questões fechadas para pesquisa com os moradores do município em estudo; e) escolha da amostra de moradores do município em estudo para aplicação do questionário; f) coleta de dados com o questionário; e, g) análise dos dados e resultados.

A coleta dos dados para o desenvolvimento deste artigo aconteceu no mês de outubro de 2006. Inicialmente, a revisão bibliográfica procurou contemplar bibliografias pertinentes bem como Leis e Normas sobre os resíduos sólidos domiciliares no estado do Paraná.

A entrevista semi-estruturada, aplicada a um encarregado do departamento de meio ambiente, foi composta de questões abertas e com roteiro para condução das mesmas. Buscando melhorar a interpretação das respostas e dos registros na entrevista, utilizou-se, com a autorização dos entrevistados, um gravador. As gravações foram transcritas ipsis literis para facilitar a análise.

O questionário foi estruturado com 5 perguntas fechadas e aplicado em 580 moradores. Os mesmos responderam ao questionário e depositaram-no em urnas. O procedimento adotado buscou assegurar sigilo sobre suas opiniões e também, segundo Triviños (1987), estabelecer um clima de confiança e empatia.

A amostra de moradores foi composta de um universo de 580 funcionários de duas empresas no município em estudo. A escolha destas empresas se deu ao fato de que o universo de funcionários está presente em $80,95 \%$ dos bairros do município em estudo. A amostra foi 
definida como não-probabilística por conveniência o que para Sâmara; Barros (1994; p.40) significa uma boa amostra, pois "são as pessoas que estão ao alcance do pesquisador e dispostas a responder a um questionário".

Procurou-se analisar os dados, fazendo a triangulação dos dados da revisão bibliográfica, entrevista e questionário. Tal procedimento tem a intenção de aumentar a compreensão do caso estudado, uma vez que "várias fontes de evidências fornecem, essencialmente, várias avaliações do mesmo fenômeno" (YIN, 2001; p.121).

\section{RESÍDUOS SÓLIDOS DOMICILIARES X MUNICÍPIO X MORADORES}

Nota-se que o município em estudo está ciente das legislações vigentes no que diz respeito aos resíduos sólidos domiciliares. Isto é melhor percebido no trecho abaixo, que relata parte da entrevista com o encarregado do departamento de meio ambiente do município:

\footnotetext{
É bom que se diga assim, que todo serviço de saneamento é de responsabilidade do município [...], mas o que nós observamos. Hoje, em termos de instrumentos municipais que disciplina, regulamenta tem alguma coisa assim na questão do entulho 'né', onde tem uma lei municipal que a responsabilidade, ou seja, que a prefeitura assume essa definição dos locais aonde podem ser postos o entulho e também a questão dos lotes baldios botando em lei a proibição da disposição de lixo nesses locais, mas o que município segue realmente é a lei federal e estadual, a estadual principalmente a $12493 / 99[\ldots]$
}

No entanto, embora tendo conhecimento das legislações vigentes, o município parece não dar a devida importância a isso, pois, cerca de metade da população do município pode estar, devido à falta do serviço de coleta seletiva, descartando resíduos, considerados pela Associação Brasileira de Normas Técnicas (ABNT), como perigosos ou inertes.

Esses resíduos, segundo a ABNT, podem causar riscos à saúde publica, provocando ou contribuindo para o aumento de mortalidade e doenças ou, ainda, dissolvido no meio ambiente e entrando em contato com o homem.

A coleta seletiva de "lixo" no município em estudo, com certeza, é um fator a ser considerado, pois, segundo Cruz (2002), este serviço facilita o reaproveitamento e a reciclagem dos mesmos. Mas, a coleta seletiva, segundo entrevistado, acontece em torno da metade da população do município.

Assim, o "lixo" que não é devidamente separado, em função da falta de coleta seletiva, pode, segundo Silva (2000), Cruz (2002), ser poluente e causar danos ao homem e ao meio ambiente.

Outro fator a ressaltar é a coleta regular de "lixo" que, segundo entrevistado, é feita em cem por cento dos moradores do município, fator que vem a confirmar dados do Instituto Brasileiro de Geografia e Estatística (IBGE) que constatou em 2002 a coleta de "lixo" em 95\% dos domicílios urbanos. 
Em se tratando do destino dos resíduos sólidos domiciliares, o município em estudo, segundo o entrevistado, tinha “[...] um lixão alguns anos atrás e, hoje, tem um aterro controlado que é uma estrutura, então, intermediária entre o aterro definitivo que o município deve instalar, 'ae' acredito que no máximo dentro de um ano [...]".

A mudança de um vazadouro a céu aberto (lixão) para um aterro controlado pode ser considerada um importante passo para o município em estudo, pois, atualmente, segundo o IBGE, 71,50\% dos municípios brasileiros utilizam "lixões" para disposição final dos resíduos sólidos domiciliares, o que, para Cruz (2002), é uma forma inadequada para disposição do "lixo".

Outro ponto a considerar é, segundo Cruz (2002), a integração do município no serviço de limpeza pública. Segundo o entrevistado, o município em estudo está fazendo campanha com diversos materiais e palestras educacionais. Porém, as ações do município, sem a efetiva participação dos moradores, não podem influenciar em todo o processo de coleta e destinação dos resíduos sólidos domiciliares.

Com objetivo de apurar os resultados qualitativos da campanha feita pelo município e da participação dos moradores em relação aos resíduos sólidos domiciliares foi aplicado um questionário, estruturado com 5 perguntas fechadas, em duas empresas do município em estudo. O total de respondentes foi de 580 moradores do município em estudo e os resultados foram:

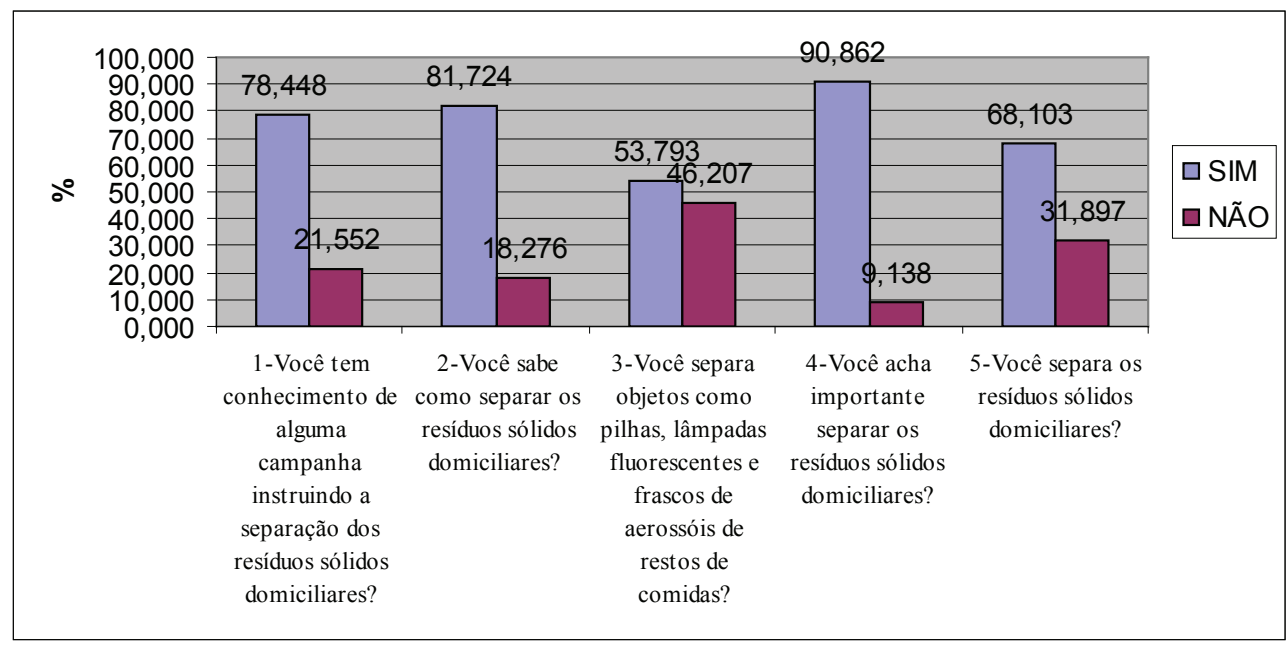

Figura 2: Moradores e os resíduos sólidos domiciliares.

Os resultados, inicialmente, mostraram que $78,45 \%$ dos respondentes têm conhecimento da campanha que o município em estudo está realizando (pergunta 1). Isto não significa, apenas, que o município está conseguindo alguns pontos positivos, mas também que os moradores têm conhecimento do que é a campanha que o município está fazendo.

$\mathrm{Na}$ seqüência, os resultados permitiram identificar um fato bastante interessante, pois $81,72 \%$ dos respondentes afirmaram que sabem como separar os resíduos sólidos domiciliares (pergunta 2). No entanto, apenas 53,79\% dos respondentes sabem que é necessário separar objetos como pilhas, lâmpadas florescentes e frascos de aerossóis dos restos de comida (pergunta 
$3)$.

Dos $81,72 \%$ que afirmam saber como separar os resíduos sólidos domiciliares, apenas $44,51 \%$ responderam "sim" à pergunta número 3. Este resultado mostra o não conhecimento dos moradores com relação aos riscos que estes objetos podem oferecer ao homem e ao meio ambiente. O município, através de campanhas, precisa pensar em ações que possam instruir melhor sobre a separação do "lixo" domiciliar.

Por fim, os resultados permitiram verificar que, embora 90,86 \% dos moradores achem importante a separação do "lixo" domiciliar (pergunta 4), somente 68,10\% dos respondentes separam (pergunta 5).

O município em estudo, embora promova a coleta regular de "lixo" em 100\% dos moradores, fazendo serviço de coleta seletiva e campanha educacional para que os moradores auxiliem na separação dos resíduos sólidos domiciliares, ainda assim não está evitando que objetos, considerados perigosos, como pilhas, lâmpadas fluorescentes, frascos de aerossóis e outros causem danos ao homem e ao meio ambiente.

Faz-se necessário ampliar o programa de coleta seletiva para garantir a correta destinação dos resíduos sólidos domiciliares e estender a campanha educacional a empresas, associações de bairros e outras entidades que possam, de alguma forma, auxiliar na organização do programa de coleta seletiva e na disseminação da campanha educacional aos moradores.

\section{CONCLUSÃO}

Os resultados deste artigo mostram que o município em estudo tem conhecimento das legislações vigentes, relacionadas à coleta e ao destino dos resíduos sólidos domiciliares; que cem por cento dos domicílios recebem a coleta regular de "lixo"; que cerca de metade dos moradores são atendidos pelo serviço de coleta seletiva; que o município está trabalhando com uma campanha educacional, procurando orientar os moradores quanto à separação do "lixo" domiciliar; e que a disposição final dos resíduos sólidos domiciliares está correta.

No entanto, dos resultados obtidos, convém salientar que o serviço de coleta seletiva atinge apenas cerca de cinqüenta por cento dos moradores. Desta forma, embora a disposição final dos "lixos" esteja correta, cerca de metade dos resíduos sólidos domiciliares produzidos no município está ganhando destino incorreto, podendo causar danos ao homem e ao meio ambiente.

Outro ponto a salientar é a campanha educacional que o município está fazendo. Embora importante a campanha, os resultados apontam que a mesma precisa ser melhorada. As resposta dos moradores ao questionário evidenciaram a falta de conhecimento do perigo que alguns resíduos sólidos domiciliares podem apresentar. Cabe ao município, ainda, estender e aprofundar a campanha de educação e orientação aos moradores. O presente artigo conclui, finalmente, e enfatiza que os resultados deste estudo de caso representam apenas uma pequena amostra diante dos "5560 municípios brasileiros". (Instituto Brasileiro de Geografia e Estatística - IBGE). 


\section{REFERÊNCIAS}

ABNT - Associação Brasileira de Normas Técnicas. Classificação de resíduos. Rio de Janeiro: ABNT, 2004.

ABNT - Associação Brasileira de Normas Técnicas. NBR 10004. Utilização de resíduos sólidos. Disponível em: http://www.abnt.org.br/NOTATECNICACONSOLIDADOFINAL.pdf . Acesso em: 10 out 2006.

CASA CIVIL DO ESTADO DO PARANÁ. Lei nº 12493. Resíduos sólidos no

Estado do Paraná. Disponível em: http://celepar7cta.pr.gov.br/SEEG/sumulas.nsf/ 9973229f063f4a8d03256c2f007a992a/7658813fa00d0c3803256e990068926c?OpenDocument . Acesso em: 10 out 2006.

CRUZ, A.L.M. A reciclagem dos resíduos sólidos urbanos: um estudo de caso. Florianópolis: UFSC, 2002. p.155. Dissertação (Mestrado em Engenharia da Produção). Programa de Pós-Graduação em Engenharia de Produção, Universidade Federal de Santa Catarina. Florianópolis.

GIL, A.C. Métodos e técnicas de pesquisa social. São Paulo: Atlas, 1999.

IBGE - Instituto Brasileiro de Geografia e Estatística. Limpeza urbana e coleta de lixo. 2000. Disponível em: http://www.ibge.gov.br/ .Acesso em: 10 out 2006.

IBGE - Instituto Brasileiro de Geografia e Estatística. Pesquisa nacional de saneamento básico. 2000. Disponível em: http://www.ibge.gov.br/ .Acesso em: 10 out 2006.

IBGE - Instituto Brasileiro de Geografia e Estatística. Projeção da população. 2004. Disponível em: http://www.ibge.gov.br/ .Acesso em: 10 out 2006.

IBGE - Instituto Brasileiro de Geografia e Estatística. Síntese de indicadores sociais. 2002. Disponível em: http://www.ibge.gov.br/ .Acesso em: 10 out 2006.

LAKATOS, E.M.; MARCONI, M.A. Fundamentos de metodologia científica. 4.ed. São Paulo: Atlas, 2001.

MONTEIRO, J.H.P.; ZVEIBIL, V.Z. Manual de gerenciamento integrado de resíduos sólidos. Rio de Janeiro: Ibam, 2001.

SAMARA, B.S.; BARROS, J.C. Pesquisa de marketing: conceitos e metodologia. São Paulo: Makron Books, 1994.

SILVA, A.S. Análise da qualidade da coleta e disposição final dos resíduos sólidos domiciliares da cidade de Ivaiporã - Estado do Paraná. Florianópolis: UFSC, 2000. 
p.115. Dissertação (Mestrado em Engenharia da Produção) - Programa de Pós-Graduação em Engenharia de Produção, Universidade Federal de Santa Catarina. Florianópolis.

TRIVINOS, A. Introdução à pesquisa em ciências sociais. São Paulo: Atlas, 1987.

YIN, R. K. Estudo de caso: planejamento e métodos. 2.ed. Porto Alegre: s.ed., 2001. 